\title{
The Prevalence of Alprazolam Uses in Geriatric Patients at Dr. Mohammad Hoesin Hospital Palembang
}

\author{
Yohanes Febrianto ${ }^{1}$, Sutomo Tanzil ${ }^{2}$, Theodorus Parulian ${ }^{2}$ \\ ${ }^{1}$ Faculty of Medicine, General Practitioner, Sriwijaya University, Palembang, Indonesia \\ ${ }^{2}$ Department of Pharmacology, Faculty of Medicine, Sriwijaya University, Indonesia
}

\begin{tabular}{l} 
Article Info \\
\hline Article history: \\
Received Dec 15, 2015 \\
Revised Feb 27, 2016 \\
Accepted Apr 02, 2016 \\
\hline
\end{tabular}

Keyword:

Alprazolam

Drug

Geriatric patients

Medical records

Prevalence

\begin{abstract}
One of the most frequently prescribed drugs in geriatric patients is a benzodiazepine, especially a short-acting such as alprazolam. Unfortunately, alprazolam is oftenly used inappropriately because this drug has a short acting effect. Geriatric patients are more sensitive to this drug that can lead to the dependence. However, there is still lack of data on the use of this drug in geriatric patients. The aim of this study was to determine the prevalence of the use of alprazolam. A drug utilization study has been done for 2 months through analysis of patient's medical records in the internal medicine ward at RSMH Palembang from June $1^{\text {st }}, 2012$ to May 31 $1^{\text {st }}$, 2013. There were 25 out of 1634 patients receiving alprazolam, but only 23 patients whose data were obtained from the available medical records. Prevalence of alprazolam use was $1.408 \%$. Based on gender, the prevalence was $1.798 \%$ in female and $1.09 \%$ in male patients. Proportion by age group was $91.3 \%, 8.7 \%$ and $0 \%$ in age group 60-74 years, 75-90 years and over 90 years, respectively. Based on the job, the population study comprised of the housewive (52.1\%), unemployment (39.1\%), and entrepreneur and farmer (4.3\% together). The indication of usage was atheroscerotic heart disease, diarrhoea and gastroenteritis of presumed infectious origin, unspecified gastritis, and thyrotoxic heart disease. In other words, it could be said that the usage of alprazolam was inappropriate.
\end{abstract}

Copyright (C) 2016 Institute of Advanced Engineering and Science. All rights reserved.

\section{Corresponding Author:}

Yohanes Febrianto,

Faculty of Medicine, General Practitioner,

Sriwijaya University,

Jl. Dr. Mohammad Ali Komplek RSMH KM 3.5, Palembang, 30126, Indonesia.

Email: Yoh_02_boyzz@yahoo.co.id

\section{INTRODUCTION}

Aging is defined as a process that transforms an adult into a weak person by reducing in most of the physiological system backup and increased susceptibility to various diseases and death [1]. Change in response to some drug occurs with increase of age in many people. Pharmacological changes in geriatric patients such as changes in the mechanism of absorption, distribution, metabolism, and elimination of drugs. Patterns of drug use are also change due to the increasing incidence of disease according to age and the tendency for doctors to prescribe excessive drugs for patients in nursing homes [2]. One of drug type that is often used in the elderly is a group benzodiazepine [3].

Data from The Drug Abuse Warning Network (DAWN) found that opioids and benzodiazepines are the two drugs that most frequently reported in cases of drug abuse [4]. Benzodiazepines are often misused as a result of their sedation effect mainly in the short-acting benzodiazepine such as alprazolam. Alprazolam is a medication used for the short term treatment of anxiety and panic disorder. This drug is not recommended as first-line because of the risk of dependence and the potentiation for misuse [5]. Beside that, alprazolam has a rapid onset and this medication is classified as a high potency drug [6]. 
Alprazolam, clonazepam, diazepam, and lorazepam are four types of benzodiazepines were recorded as 200 drugs that are most frequently used in USA [7],[8]. Meanwhile, the National Forensic Laboratory System (NFLIS) said that there was an increase in the use of alprazolam by 75\% from 2001 until 2005 [9].

The short acting effect, high potential and short half-life of alprazolam allows users to continuously use this drug even outside of the treatment due to the occurrence of dependence. Beside that, alprazolam is often prescribed inappropriately and outside of the indications. These drugs included in the Beer's criteria 2012 of Pottentially Inappropriate Prescriptions for Elderly because there is high incidence of improper administration of alprazolam. The use of alprazolam increased in elderly patients related to the problem that often encountered in elderly such as sleep disturbance and anxiety. Data from epidemiological and experimental studies mentioned that the elderlys are more sensitive to the central nervous system effects of benzodiazepine [10]. This statement indicates that the benefit of BZD use in the elderly is still unclear. Cumming et al., (2003) [11] concluding that benzodiazepine prescription should be limited in geriatric patients and the elderly who have been taking this drug should start trying to reduce the usage under hospital supervision.

Based on the data above, the study aim was to determine the prevalence of alprazolam use to geriatric patients at the General Hospital Mohammad Hoesin Palembang on June $1^{\text {st }}$, 2012- May $31^{\text {st }}, 2013$ period to prove the truth of the reality because there is tendency of alprazolam inappropriate prescription accoring to the Beers criteria in 2012 and the dependence effets of the use of these drugs in the long term treatment.

\section{RESEARCH METHOD}

The study protocol has approved by ethical committee of medical faculty of Sriwijaya University. This research was conducted at the General Hospital of Muhammad Hoesin Palembang, South Sumatera, Indonesia for 2 months through analysis of medical records of patients aged $>60$ years as the population who are hospitalized in internal medicine wards A to F on 1 June 2012 - 31 May 2013 period. Patient medical records which have unclear information or illegible are excluded from this research.

There was 1634 geriatric inpatient which found through computerized system of RSMH inpatient medical record. Then, through pharmacy computerized system we search for the patient who received alprazolam during treatment.

We enter the patient's medical record number to computer and we get patient pharmacy data during hospitalization. Through these searches, we found 25 geriatric patients who receive alprazolam. Then, we look for the patient's medical records of patients who had been identified in the medical record computerized system. However, after a search through medical records, two data are not found so there are only 23 data which we use in this research as a subject.

Medical records are then studied to match the computerized search results with the original data, then we recorded all patient data that are needed, particularly variable in this study that are age, gender, occupation, indications, and side effects of treatment. Then, the data obtained are included in the SPSS system to facilitate the reading of data. The results in this study are presented in the form of tables and graphs with the narrative.

\section{RESULTS AND DISCUSSION}

From 1634 geriatric patients, the majority of hospitalized patients were in the age group of 60-74 years (1365/83.5\%). The total of 911 patients were male $(55.7 \%)$ and the remaining 723 patients are female (44.2\%). Population's sociodemographic data can be seen in Table 1.

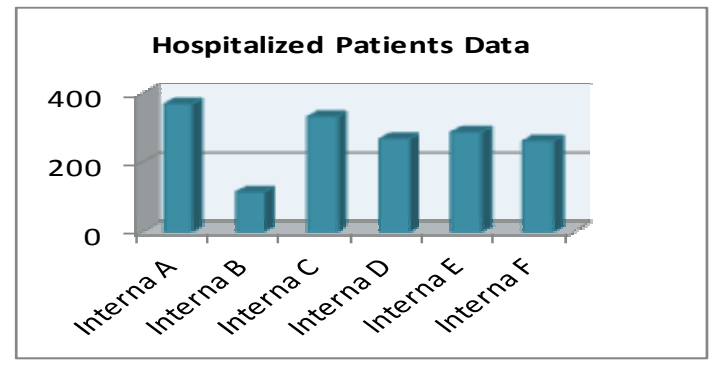

Figure 1. Hospitalized Patients in Each of Ward 
From the 1634 patients, there were 23 patients who received alprazolam, so that the prevalence of use of these drugs was $1.408 \%(23 / 1634)$ (Table 2). The results of this study indicate that most of the alprazolam use was in the age group 60-74 years (21/91, 3\%), followed by age group 75-90 (2/8.7\%), while at the very old age group ( $>90$ years) there is no use of alprazolam.

Table 1. Population's Sex and Age Distribution

\begin{tabular}{lcc}
\hline & Total $(\mathbf{n}=\mathbf{1 6 3 4})$ & Percentage $(\mathbf{n}=\mathbf{1 0 0 \%})$ \\
\hline Age & & \\
$\mathbf{6 0 - 7 4}$ year & 1365 & 83 \\
$\mathbf{7 5 - 9 0}$ year & 259 & 15.9 \\
$\quad>\mathbf{9 0}$ year & 10 & 0.6 \\
Sex & & \\
$\quad$ Male & 911 & 55.8 \\
Female & 723 & 44.2 \\
\hline
\end{tabular}

The total of 13 patients was women (56.5\%) and the remaining 13 were men (43.5\%). Based on these data we can determine that the prevalence of use in women is $1.798 \%(13 / 723)$ and men are $1.09 \%$ (10/901). This suggests that more woman recieve alprazolam than man.

For job variable, alprazolam most widely administered to women who work as housewives (52.1\%; 12), followed by patients who are not working due to old age (39.1\%;9), and last, the self-employed and farmer $4.3 \%$, respectively (1 patient). The sociodemographic data can be seen in Table 3 .

Alprazolam was given to hospitalized patients in internal medicine wards for various indications according to ICD 10 criteria. From these results they appear that the diagnosis in patients spread without any dominant disease. Alprazolam was administered in patients with an indication of atheroscerotic heart disease, diarrhoea and gastroenteritis of presumed infectious origin, dyspepsia, unspecified gastritis, and thyrotoxic heart disease (THD) / thyrotoxicosis / unsspecified, two cases respectively (8.7\%). While the rest which are acute myocardial infarction, anaemia, asthma, chronic obstructive pulmonary disease, chronic renal failure, congestive heart failure (CHF), eseential (primary) hypertension, gastric ulcer, hypertensive heart disease without (congestive) heart failure, non-insulin dependent diabetes mellitus, other diseases of digestive system (melaena), other gastritis, and volume depletion is only a single case (4.3\%). Data indicative of alprazolam administration can be seen in Table 4 .

Table 5 shows that the entire uses of alprazolam were improper (100\%) because there were a lack of records or a through assessment in anxiety disorders and panic attacks in the patient's medical record, while alprazolam only indicated for panic attacks and generelized anxiety disorder. These data indicate that there is Potentially Inappropriate Prescriptions (PIP) in geriatric patients.

Alprazolam is given outside of the main indications given above and this drug just use based on another effect of the nature of this drug work which basically does not fit in the context of rational treatment. Meanwhile, when viewed from the primary diagnosis, the appropriateness of the prevalence can not be assessed directly, because all patients were treated over the main indications and alprazolam mostly just a symptomatic drug against the patient's complaint.

Table 2. Prevalence Use of Alprazolam

\begin{tabular}{ccccc}
\hline & n Receive & n Not Receive & \% Receive & \% Not Receive \\
\hline $\mathbf{2 6 0}$ year & 23 & 1611 & 1.408 & 98.592 \\
Male & 10 & 901 & 1.09 & 98.902 \\
Female & 13 & 710 & 1.798 & 98.202 \\
\hline
\end{tabular}

Side effects of treatment can not be found in the medical records because the side effects of treatment are not written by doctors and nurses who treated patients. This is due to the large number of hospitalized patients in and out every day, so that the medical team difficult to follow up all the patients.

\subsection{Discussion}

From the Table 2 above, known that the prevalence of the use of alprazolam in geriatric patients are $1.408 \%$, or 23 of the 1634 patients who were hospitalized. This figure shows that the use of alprazolam is low. However, use of these drugs should be also reviewed not only by its numbers but also from the indication or the reason why doctor choose this drug. Reconnexion (2010) mentions that the elderly aged over 65 years get prescription of benzodiazepines as much as 11\%, more than the adult population which

The Prevalence of Alprazolam Uses in Geriatric Patients at Dr. Mohammad Hoesin .... (Yohanes Febrianto) 
only 5\% [12]. The study result of Nakao et al. (2009) [13] also found more elderly patients received this drug class than young adults.

Table 3. Socio Demographic Data of Alprazolam User

\begin{tabular}{lcc}
\hline & Total $(\mathbf{n}=\mathbf{2 3})$ & Percentage $(\mathbf{n}=\mathbf{1 0 0} \%)$ \\
\hline Age & & \\
60-74 year & 21 & 91.3 \\
75-90 year & 2 & 8.7 \\
$\quad>90$ year & 0 & 0 \\
Sex & & \\
$\quad$ Male & 10 & 43.5 \\
$\quad$ Female & 13 & 56.5 \\
Jobs & & \\
$\quad$ Not Work & 9 & 39.1 \\
Housewives & 12 & 52.1 \\
Farmer & 1 & 4.3 \\
Entrepreneur & 1 & 4,3 \\
\hline
\end{tabular}

Khawaja et al (2005) [14] in Pakistan researching benzodiazepines prescription in hospitalized patients, and they got result that among the class of benzodiazepine, alprazolam was the second most commonly prescribed in the amount of $11.4 \%$ (44). On the prevalence, of the use of alprazolam in that study were $2,404 \%(5 / 208)$. This suggests that the prevalence of the use of alprazolam in RSMH still low compared with this study. Khawaja's research also found that the department of internal medicine is the departement where most patients took benzodiazepine ( $22.7 \%$ of 44 patients). The amount of use of alprazolam in internal medicine wards achieving $10 \%$ of the 208 patients. Prevalence of alprazolam administration in this study is still low when compared to research conducted by Vali et al (2012) [15] in Iran which found that the prevalence use of alprazolam is about $3.302 \%$ (7/212).

Based on Table 3, it can be concluded that the group of 60-74 years was the most group who receive alprazolam (91.3\%) which may be associated with an average life expectancy of people in South Sumatra. In the 75-90 year age group, there are 2 uses (8.7\%), while at the very old age group ( $>90$ years) there is no use of alprazolam. This is consistent with research conducted by Nakao et al. (2009) [13] who find out that the 65-74 year age group is the most group that received benzodiazepine (5355 patients).

The calculation in Table 2 shows that the prevalence use of alprazolam in men group amounted to $1.09 \%$ and the use in the female group is $1.798 \%$. This is consistent with data from the WHO document On Substance Abuse Program (1996) [16] which states that the benzodiazepine prescriptions doubled in female patients than male patients. Similar data were presented by Reconnexion (2010), the group that experienced in the treatment of patients who get dependence to benzodiazepine in Victoria, that the class of benzodiazepine prescribed more in female patients than male [12].

Table 4. Alprazolam Indications

\begin{tabular}{lcc}
\hline & Total (n=23) & Percentage (100\%) \\
\hline Acute Myocardial Infarction, Unspecified & 1 & 4.3 \\
Anaemia.Unspecified & 1 & 4.3 \\
Asthma Unspecified & 1 & 4.3 \\
Atherosclerotic Heart Disease (Cad) & 2 & 8.7 \\
Chronic Obstructive Pulmonary Disease, & 1 & 4.3 \\
Unspecified & & 4.3 \\
Chronic Renal Failure,Unspecified & 1 & 4.3 \\
Congestive Heart Failure (Chf) & 1 & 8.7 \\
Diarrhoea \& Gastroenteritis Of Presumed Infectious & 2 & 8.7 \\
Origin & & 4.3 \\
Dyspepsia & 2 & 4.3 \\
Eseential (Primary) Hypertension & 1 & 8.7 \\
Gastric Ulcer & 1 & 4.3 \\
Gastritis, Unspecified & 2 & \\
Hypertensive Heart Disease Without (Congestive) & 1 & 4.3 \\
Heart Failure & & 4.3 \\
Non Insulin Dependent Diabetes Mellitus & 1 & 4.3 \\
Other Diseases Of Digestive System => Melaena & 1 & 8.7 \\
Other Gastritis & 1 & 4,3 \\
Thyrotoxic Heart & 2 & \\
Disease(Thd)/Thyrotoxicosis/Unsspecified & & \\
Volume Depletion & 1 & \\
\hline
\end{tabular}

IJPHS Vol. 5, No. 2, June 2016: 193 - 200 
Nakao et al [13] also found that female patients receive more benzodiazepine prescriptions than men in hospitalized patients in various departments (21.6\%: $18.6 \%)$ and the percentage was increasing according to the age. This is similar to the results of Raoof et al. [17] research in Pakistan which found that more female patients get benzodiazepine than the male patients (37.8\%: 25.3\%) and users are more likely in older age. More number of prescribing in female patients may be due to the longer life expectancy of female than male [18].

In job variable, these results are also consistent with studies of Raoof et al [17] who found that the housewife is the most work groups which getting alprazolam in their life in Pakistan. That research was linking marital status as the psychosocial correlation with mental disorders. Khawaja et al [14] also found the same thing that housewife is the most group of inpatients who received benzodiazepines.

Copernicus Knowledge System at UK in Isbister [19] provide data of alprazolam administration in general patients during June $1^{\text {st }}, 2002$ to September $30^{\text {th }} 2002$ period by a general practitioner. The data obtained shows that the indication of alprazolam prescription as follows: 310 cases of panic disorder (48\%), 194 cases of anxiety (30\%), depression 18 cases (2.6\%), anxiety / depression 26 cases (4\%), insomnia 9 cases (1.6\%), other 80 cases (12\%), and no indication 194 cases. These data suggest that administration of alprazolam outside of the main / imprecise indication can reach 107 cases (9 cases of insomnia, depression 18 cases, and other 80 cases).

Table 5. The Proportion of Precise or Imprecise Indication

\begin{tabular}{ccc}
\hline & Total $(\mathbf{n}=\mathbf{2 3})$ & Percentage $(\mathbf{1 0 0 \% )})$ \\
\hline Precise & 0 & 0 \\
Imprecise & 23 & 100 \\
\hline
\end{tabular}

Nakao et al [13] in Japan conducted a study of hospitalized patients who received benzodiazepines in the hospital. The result obtained that the most patient who took benzodiazepine are patients with indication of chronic renal failure (31.3\%), followed by heart failure (29.3\%), acute myocardial infarction (28.9\%), malignant neoplasm of the liver and intrahepatic bile ducts (28.0\%), post-procedural disorders of the nervous system (28.0\%), malignant neoplasm of the bronchus and lung (27.7\%), noninsulin-dependent diabetes mellitus (25.0\%), and malignant neoplasm of the bladder (22.2\%).

Meanwhile, Khawaja et al [14] found in his research that anxiety, insomnia, agitation, and depression are the reason that doctors use for prescribing alprazolam in hospitalized patients at Pakistan Teaching Hospital. Divac et al [20] also found that the class of benzodiazepines often administered to patients with cardiovascular problems and non-psychiatric diseases without the possibility of an anxiety disorder or other indications of benzodiazepine administration.

The tendency of the alprazolam wrong prescription or included in the category of PIP also occur in research conducted by Tobat [21] who found eight geriatric patients who were treated at the department of internal medicine wards at DR. M. Djamil Hospital Padang got alprazolam outside of its truly indications. In that study the side effects of treatment occurred in two patients who undergo treatment with alprazolam. Tobat research using a prospective method for 3 months so that the side effect can be observed, in contrast to these studies that use descriptive method through analysis of medical records so that the side effects of treatment can not be found.

The use of alprazolam as a form of inappropriate treatment is also found in the study of Akazawa et al. [22] in Japan. That study provided data of 10 class drugs which most often included in the Potenttialy Inappropriate medication in elderly patients and the benzodiazepine is the class number two of drugs commonly prescribed inappropriately (11.4\% (756/6628)), with a short-acting class as much as 3.3\% or 222 patients. This suggests that there is a trend in the wrong prescription alprazolam in geriatric patients in various countries.

However, further research by Akazawa et al. (2012) [23] in Japan through the recipe analysis also found that there is a trend of alprazolam improper prescribing in geriatric patients according to the criteria of beers in 2012. Akazawa et al found there were 24 (7.3\%) patients taking alprazolam outside the main indication. Nakao et al [13] also stated that the benzodiazepine class of drugs is very often administered in the hospital without documentation of the indications. Elliot et al [24] also found that inappropriately benzodiazepine prescribing reach $16 \%$ of $36 \%$ prescription.

Side effects of alprazolam in the treatment of hospitalized patients in this study could not be confirmed through medical record because the side effects were not written by a medical team in the care process. However, some common side effects in patients treated with alprazolam are seizures, loss of coordination (ataxia), and difficulty on concentrating, memory impairment/transient amnesia, hallucinations,

The Prevalence of Alprazolam Uses in Geriatric Patients at Dr. Mohammad Hoesin .... (Yohanes Febrianto) 
depersonalization, taste disorders, dystonia, irritability, anorexia, fatigue, sedation, musculoskeletal weakness, and incontinence.

Beer's criteria in 2012 advocated a focus on the use of benzodiazepines, in this case the class of short-acting benzodiazepne; alprazolam. Beer recommend to avoid the use of benzodiazepines to treat patients with insomnia, agitation, and delirium because the elderly have increased sensitivity to benzodiazepines and increase the risk of cognitive impairment, delirium, falls, fractures, and accidents [25].

Alprazolam only indicated for patients with generalized anxiety disorders/GAD and panic attacks with or without agorapobia. However, in fact, alprazolam often prescribed to patients with complaints of difficulty sleeping (insomnia), especially by general practitioners [16]. However, in geriatric patients theirselves, specifically for GAD and panic attacks, alprazolam should be avoided because treatment with this drug will cause side effects such as falls, impaired memory and accumulation effects on the body. It is as formulated by the Western Australian Psychotropic Drugs Committee [26] and The College of Psychiatry of Ireland (2012) [27] that suggest to use selective serotonin reuptake inhibitors (SSRIs) in the case of anxiety disorders in the geriatric patient groups rather than alprazolam and avoid the use of all types of benzodiazepine.

Table 6. Respondents's Characteristics

\begin{tabular}{|c|c|c|}
\hline Variable & Total $(n=23)$ & Percentage (100\%) \\
\hline \multicolumn{3}{|l|}{ Sex } \\
\hline Male & 10 & 43.47 \\
\hline Female & 13 & 56.53 \\
\hline \multicolumn{3}{|l|}{ Age } \\
\hline $65-74$ year & 21 & 91.31 \\
\hline 75-90 year & 2 & 8.69 \\
\hline$>90$ year & 0 & 0 \\
\hline \multicolumn{3}{|l|}{ Dosage } \\
\hline $0,5 \mathrm{Mg}$ & 13 & 56.53 \\
\hline $1 \mathrm{Mg}$ & 10 & 43.47 \\
\hline \multicolumn{3}{|l|}{ Frequency } \\
\hline 1 X 1 day (night) & 23 & 100 \\
\hline \multicolumn{3}{|l|}{ Duration of drug use } \\
\hline 1 day & 2 & 8.69 \\
\hline 2 days & 4 & 17.39 \\
\hline 3 days & 3 & 13.04 \\
\hline 4 days & 1 & 4.34 \\
\hline 5 days & 4 & 17.39 \\
\hline 5 days (brought home) & 3 & 13.04 \\
\hline 6 days & 2 & 8.69 \\
\hline 9 days & 1 & 4.34 \\
\hline 13 days & 1 & 4.34 \\
\hline 15 days & 1 & 4.34 \\
\hline 15 days (brought home) & 1 & 4.34 \\
\hline \multicolumn{3}{|c|}{ Patient's complaint/ symptom } \\
\hline Cough & 1 & 4.3 \\
\hline Nervous & 1 & 4.3 \\
\hline Chest pain & 2 & 8.7 \\
\hline Epigastric pain & 1 & 4.3 \\
\hline Joint pain & 1 & 4.3 \\
\hline Heartburn & 1 & 4.3 \\
\hline Headache & 1 & 4.3 \\
\hline Shortness of breath & 2 & 8.7 \\
\hline No indication & 2 & 8.7 \\
\hline Can’t sleep & 9 & 39.1 \\
\hline Not known & 2 & 8.7 \\
\hline
\end{tabular}

Based on this recommendation, the actual administration of alprazolam in geriatric patients in internal medicine wards RSMH is improper when viewed from two sides, from the insomnia that is clearly wrong and from security aspect of the main indications (GAD and panic attacks). Nonetheless, some other guideline still allows the use of alprazolam in geriatric patients, but with some special attention, such as dose, duration of use, and interaction.

There are several reasons why the improper administration of alprazolam may occur in the geriatric patient, such as the condition of the patients themselves and the factors that are derived from the physician (knowledge on the panel criteria, adherence to the guidline, and dependents for a pharmaceutical company) [28]. 
Meanwhile, according to Moylan et al (2012) there are several reasons for the wrong prescription of alprazolam that are due to physician preference contrary to treatment guidelines, such as skepticism, lack of awareness and understanding of the principles of guidance, lack of expectations of treatment outcomes, and the existence of a pattern of practice habits (unable or unmotivated to change practice patterns), as well as the patient's own preferences (in this case the dependence).

The clinicians desire to quickly relieve the patient's complaints (such as insomnia) and existing behavioral patterns [6], make alprazolam become the first choice for addressing patient complaints that cause the prevalence use of alprazolam in geriatric patients at RSMH Palembang was $1.408 \%$.

The limitation of this study is that the researchers are not able to directly assess the reasons why doctors give alprazolam to patients, so that researchers could only formulate it in the form of the main indications and patient complaints during the treatment process as presented in the table and the description above.

Regardless, the prevalence use of alprazolam in geriatric patients in internal medicine wards RSMH is still low compared to similar studies that have been done. This is possibly because the use of alprazolam was more in outpatients than inpatients setting. In addition, the study shows that clobazam is more widely used than alprazolam in dealing with problems of patients during the treatment process.

However, the persistences of the use of alprazolam are inclined towards Potenttialy Inappropriate Medication (PIM) according to criteria of Beer's shows that there were still a problem in the pattern of drug administration in geriatric patients and these things can be very dangerous because it can lead to the emergence of the problem such as dependence, tolerance, and the effects of drug withdrawal in the future.

\section{CONCLUSION}

We can conclude that the prevalence use of alprazolam is 1,408\% with the $60-74$ year age group is the largest group who received alprazolam (21 patients: 91.3\%). More female patients getting alprazolam than male patients with a prevalence ratio of $1.798 \%: 1.09 \%$. In job variable, most patients are housewives (52.1\%). Most of alprazolam give to patients with complaints of atheroscerotic heart disease, diarrhoea and gastroenteritis of presumed infectious origin, dyspepsia, unspecified gastritis, and thyrotoxic heart disease (THD)/thyrotoxicosis/unsspecified. It can be concluded that all of alprazolam prescription was given outside a medical indication (no exact indication). While the side effects of the treatment could not be reported in this study due to side effects of treatment does not include the medical record.

\section{ACKNOWLEDGEMENTS}

The author would like to thank the Faculty of Medicine, Sriwijaya University, medical record team, and all those who helped in the implementation of this research.

\section{REFERENCES}

[1] Setiati S., et al., "Proses Menua dan Implikasi Klinisnya. Dalam: Sudoyo AK," Buku Ajar Ilmu Penyakit Dalam, Jakarta Pusat, Internapublishing, pp. 757-767, 2009.

[2] Katzung B. G., "Farmakologi Dasar dan Klinik : Aspek Khusus dalam Farmakologi Geriatrik,” edisi ke 10, Terjemahan oleh: Nugroho A. W., Jakarta, Penerbit Buku Kedokteran EGC, pp. 1020-1028, 2007.

[3] Baum C., et al., "Drug utilization in the US, Seventh Annual Review," Food and Drug Administraton, center for drugs and biologics, pp. 1-41, 1985.

[4] Tan K. R., et al., "Hooked an Benzodiazepines: GABA $A_{A}$ receptor subtypes and addiction,” Trends in Neuroscience, vol/issue: 34(4), pp. 188-197, 2011.

[5] Rinstood A. C., et al., "Recent Increase in detection of Alprazolam in Victorian Heroin-Related Deaths,” MJA, vol. 198, pp. 206-209, 2013.

[6] Moylan S., et al., "The role of Alprazolam for the treatment of panic disorder in Australia,” Aust N Z J Psychiatry, vol. 46, pp. 212-224, 2012.

[7] Salzman C., “Addiction to benzodiazepine," Psy. Quart, vol. 69, pp. 251-261, 1998, in "Hooked an Benzodiazepines: GABA $\mathrm{A}_{\mathrm{A}}$ receptor subtypes and addiction,” Trends in Neuroscience, vol/issue: 34(4), pp. 188-197, 2011.

[8] Schull P., "Nursing Spectrum Drug Handbook. McGraw Hill,” in Hooked an Benzodiazepines: GABA $\mathrm{A}_{\mathrm{A}}$ receptor subtypes and addiction, Trends in Neuroscience, vol/issue: 34(4), pp. 188-197, 2011.

[9] Strom K. J., et al., "NFLIS special report: controlled prescription drugs, 2001-2005,” Washington DC, U.S. Drug Enforcement Administration, 2006.

[10] Dipiro J. T., et al., "Geriatric," in Pharmacotherapy:A patophysiology Approach. 7th edition, New york, mcgraw hill, pp. 57-66, 2008.

[11] Cumming R. G. \& Le Couteur D. G., "Benzodiazepines and risk of hip fractures in older people: a review of the evidence,” CNS drugs, vol. 17, pp. 825-837, 2003.

The Prevalence of Alprazolam Uses in Geriatric Patients at Dr. Mohammad Hoesin .... (Yohanes Febrianto) 
[12] Reconnexion, “Beyond Benzodiazepine,” 222 Burke Road, Glen Iris 3146, pp. 1-71, 2010.

[13] Nakao M., et al., "Benzodiazepine prescription and length of hospital stay at a Japanese university hospital," BioPsychoSocial Medicine, vol/issue: 3(10), pp. 1-7, 2009.

[14] Khawaja M. R., et al., "Prescription pattern of benzodiazepines for inpatients at a tertiary care hospital in Pakistan," J Pak Med Assoc, vol/issue: 55(6), pp. 259-63, 2005.

[15] Vali L., et al., “An Investigation on Inappropriate Medication Applied among Elderly Patients,” World Applied Sciences Journal, vol/issue: 16(6), pp. 819-825, 2012.

[16] World Health Organization (WHO), "Programme on Substance Abuse: Rational Use of Benzodiazepine,” pp. 1-39, 1996.

[17] Raoof M., et al., "Awareness and Use of Benzodiazepines in Healthy Volunteers and Ambulatory Patients Visiting a Tertiary Care Hospital: A Cross Sectional Survey,” PLOS ONE, vol/issue: 3(3), pp. 1-5, 2008.

[18] British Columbia Ministry of Health, "The Health and Well-Being of Women in British Columbia: Provincial Health Officer’s 2008 Annual Report,” Victoria, Office of the Provincial Health Officer, 2008.

[19] Isbister G. K., et al., "Alprazolam is relatively more toxic than other benzodiazepines in overdose," BR $J$ Clin Pharmacol, vol. 58, pp. 88-95, 2004.

[20] Divac N., et al., “Utilization of psychiatric drugs in Serbia,” Vojnosanitetski Pregled, vol/issue: 66(3), pp. 233-237, 2009.

[21] Tobat S. R., "Identifikasi PIP (Potentially Inappropriate Prescription) dan ADR (Adverse Drug Reactio) pada Pasien Geriatri di Bagian/SMF Rawat Inap Penyakit Dalam RSUP. DR. M. Djamil Padang,” Tesis, Program Studi Farmasi Peminatan Komunitas dan Klinis Program Pascasarjana Universitas Andalas Padang, 2011.

[22] Akazawa M., et al., "Potentially Inappropriate Medication Use in Elderly Japanese Patients," The American Journal of Geriatric Pharmacotherapy, vol/issue: 8(2), pp. 146-160, 2010.

[23] Akazawa M., et al., "Drug Utilization Reviews by Community Pharmacists in Japan: Identification of Potential Safety Concerns through the Brown Bag Program,” Value in Health Regional Issues, vol. 1, pp. 98 - 104, 2012.

[24] Elliott R. A., et al., "Improving benzodiazepine prescribing for elderly hospital inpatients using audit and multidisciplinary feedback,” Intern Med J, vol/issue: 31(9), pp. 529-35, 2011.

[25] American Geriatrics Society, "American Geriatrics Society Updated Beers Criteria for Potentially Inappropriate Medication Use in Older Adults,” The American Geriatrics Society 2012 Beers Criteria Update Expert Panel, 2012.

[26] Western Australian Psychotropic Drugs Committee, “Anxiety Disorders Drug Treatment Guidelines,” Western Australia Department of Health, 2008.

[27] The College of Psychiatry of Ireland, "A consensus statement on the use of Benzodiazepines in specialist mental health services,” 2012.

[28] Fialová D., et al., "Potentially Inappropriate Medication Use Among Elderly Home Care Patients in Europe," JAMA, pp. 293, 2005. 